\title{
GERMINAÇÃO DE SEMENTES DE PHYSALIS ARMAZENADAS EM DIFERENTES EMBALAGENS E PERÍODOS
}

\author{
Paloma Francisca Pancieri de Almeida ${ }^{1}$ \\ Graziela Evencio de Oliveira² \\ Jalille Amim Altoé Freitas ${ }^{3}$
}

Resumo: Objetivou-se avaliar o efeito do uso de diferentes materiais de armazenamento na germinação de sementes de Physalis peruviana L. As sementes foram submetidas a três métodos de armazenagem: embalagem de papel Kraft (T1), embalagem de plástico (T2) e embalagem hermética de vidro com tampa de plástico (T3). Os diferentes tratamentos foram mantidos sob mesma condição de temperatura e sombreamento por 30, 45 e 60 dias. O experimento foi estabelecido como delineamento inteiramente casualizado. Os tratamentos não influenciaram na porcentagem de germinação, já no IVG, a embalagem de plástico apresentaram maiores valores, tanto em 30, 45 e 60 dias de período de armazenamento. 0 material da embalagem utilizada para armazenamento de sementes de Physalis influencia na velocidade de germinação, sendo que a embalagem de plástico apresentou IVG superior à demais, principalmente aos 30 dias de armazenamento, sendo assim, através dos resultados a mais indicada para armazenagem das sementes.

Palavras-chave: Índice de Velocidade de Germinação; Porcentagem de Germinação; Papel kraft; Plástico; Vidro.

\footnotetext{
1 Agronomia/ Universidade Federal do Espírito Santo, Brasil. E-mail: paloma.panci@hotmail.com.

2 Agronomia/ Universidade Federal do Espírito Santo, Brasil. E-mail: grazievencio_@hotmail.com.

${ }^{3}$ Agronomia/ Universidade Federal do Espírito Santo, Brasil. E-mail: jalilleamim@yahoo.com.br.
} 